of dealers. But the editors have done something with them, and they have handled the more lasting forms with a rather surprising fulness of treatment.

Nomenclature, which is a source of some concern and more confusion to botanists, has been conformed, more or less consistently, to the more conservative horticultural and botanical views. It could not give satisfaction in any case, and it has at least the merit of simplicity as it has been handled.

In a word, whatever one would most reasonably look for in a Cyclopedia of American Horticulture, is to be found in Professor Bailey's book. While good things may have been omitted from it, the present reviewer has not found bad things that have been introduced into it; and it is worthy of a place where not only gardeners and botanists, but school-children may see it daily.

Wm. Trelease.

La nature tropicale. By J. Constantin. Paris, Felix Alcan, Ed. Pp. 315, figs. 166. 1899. The first chapter of this book is chiefly comprised of selections from the expressions of various naturalists on their first encounter with the forests and jungles of the tropics, and the second analyzes the principle factors in the equatorial climate. Succeeding chapters are devoted to trees and their architecture, foliage, periodicity, flowers and fruits, the tropical forest in previous geological epochs, climbers of all kinds, parasites and parasitic action of flowers, saprophytes and epiphytes, co-operation of ants, influence of the sea, the mangrove, the flora of islands and the final chapter is a singular mixture of fanciful conceptions relative to the earlier history of the earth and the cos. mos, with enough of an admixture of mythology and tradition to endear it to readers of tender years. The general style of the book is not unpleasant, and although most of it might have been written a decade since, yet some recent results have crept into the discussions, especially in regard to the more sensational discoveries in botany. A table of contents placed at the end of the book does not redeem the lack of a suitable index.

\section{T. MacDougaL.}

Fossil Flora of the Lower Coal Measures of Missouri. By DAVID WHITE. Monographs of the United States Geological Survey, Vol. XXXVII. Washington. 1899. 4to, cloth. Pp. 467 ; pls. 73.

This work is based upon material collected by Dr. J. H. Britts and by geologists of the Missouri and United States Geological Surveys, in Henry county, Missouri.

It may be regarded from either the point of view of the geologist or from that of the paleontologist, but it is essentially a contribution to paleo-botany in which the facts are utilized for purposes of correlation and comparison between the coals of Missouri and those of the Eastern United States and Europe.

The species enumerated are 124. Of these 10 are gymnosperms, 1 (Palaeoxyris) is classed provisionally under 'Animalia?' and the remainder are cryptogams, most of them previously described. The discussion and table of synonomy under each genus and species is exceedingly full and a number of changes in nomenclature are made in order to bring it into harmony with modern ideas on the subject. The systematic arrangement is in accordance with the botanical affinities and sequence of the species and families.

Several innovations may be noted in the matter of illustrations. The figures are mainly reproductions of photographs of the rock containing the species, accompanied by drawings of portions of the species in which details of outline, nervation or fructification, etc., are shown. This method gives a good general idea of the actual appearance of each specimen as a whole together with the particular features which require emphasis, but such plates are not equal, for purposes of exact study, to reproductions from carefully made drawings, as may be seen by a comparison between Plates XL. and XLI. Another innovation which has produced excellent results is in the line of enlarged photographic reproduction, an example of which may be seen on Plate LI.

In the final discussion of the flora there are tables of distribution, for purposes of comparison with other coal floras and the conclusion is reached that the stratigraphic position of the Henry county coals is subsequent to the lower 